\title{
Differences between Chinese Socialist Value Outlook and Western Mainstream Value
}

\author{
Yuxia Ding \\ Wuhan Donghu University, Wuhan 420212, China
}

Keywords: Socialist value outlook, Western mainstream value, Cultural difference

\begin{abstract}
With penetration and influence of western mainstream value, Chinese socialist value outlook is promoted to make some changes, so as to adapt to social development needs. At the same time, we should guarantee advancement of socialist ideology, so as to guarantee stable and healthy socialist development. While accepting western mainstream value, we should convert its superior parts, so as to promote continuous improvement to Chinese socialist value outlook. Facing western mainstream value, we should show respect, seek common points while reserving difference, and allow our socialist value outlook standing in the forest of world ideology. Thus, we can clearly see advantages and disadvantages of our cultural values, so as to promote development of our socialist culture and give correct guidance. International social competition becomes more and more fierce. National cultural soft power is an important pattern of manifestation for comprehensive national strength. At the same time, we should also pay attention to differences between socialist value outlook and western mainstream value. This is an essential link for promotion of exchange and cooperation between different countries.
\end{abstract}

\section{Preface}

Formation and development of socialist value outlook is resulted from continuous exploration and practice for advanced thoughts in the course of historical development. This is the summary and statement of our historical development. At the same time, it is also an important guideline for our socialist development as well as a fundamental philosophy for realization of Chinese nation's great rejuvenation. Economic globalization makes it wider and more frequent for exchange between different countries. When the society is full of numerous western cultural thoughts, we should have deep understanding and develop our socialist value outlook, and find differences between our values and western cultural values in the current development process. Moreover, we should also pay attention to cultural differences, and avoid cultural conflicts, so as to promote our stable and healthy development. Under the current development background in China, we should see differences and know ourselves as well as other countries. This will plays an important role in promoting better development. While respecting differences, we should also stably improve social ${ }^{[1]}$ and cultural soft power, promote China's advancement in world cultural exchange, and provide strong guarantees to our cultural development and exchange.

\section{Analysis on Connotation and Structure of Socialist Value Outlook}

Value and value orientation refer to the summary of people's views of ideas, interests, needs and ideologies while facing environmental changes around the world. However, human's behaviors usually refer to social activities on the basis of following values. Therefore, people's manners and cognitions in the face of the world are closely correlated with their world outlook. Development of our socialist value outlook is a process of continuous improvement. China's social value system takes Marxism as the guiding thought. Common ideal of socialism with Chinese characteristics takes patriotism as the core, including time spirit with national spirit and reform and innovation as the core as well as socialism outlook for honor and dishonor. With convening of the Eighteenth Congress of the Communist Party of China, the core contents of our socialist value outlook were unscrambled. Moreover, it also proposed the socialist core value of "prosperity, democracy, civilization, harmony, 
freedom, equality, justice, ruling by law, patriotism, professionalism, good faith and friendly". These thoughts formed in social practice are served as guiding thoughts and fundamental bases for us to carry forward and implement socialist value outlook. At the same time, this advanced socialist core value is also served as the foundation and thought foothold for facing cultural impacts from foreign countries.

\section{Analysis on socialist value outlook}

Development of socialist value outlook is matched and mutually promoted with people's social practice. As advanced development guiding thought in China, it reflects the thought of socialist society. It reflects social centripetal force and cohesive force in value identification standards, essentially manifesting fundamental characteristics of socialist society. Viewed from the content of socialist value outlook, we can divide it into ordinary and special provisions. Both provisions are divided on the basis of socialist principles. At the same time, special provision is a value system conforming to specific nations, countries and conditions. It is a specific application means of socialist value outlook. In other words, ordinary provision makes a clear distinction for principle boundaries of special provision. However, special provision proposes supplementation and completion for development of ordinary provision. According to the contents and statements for socialist core values proposed on the Sixth Plenary Session of the Sixteenth Congress of the Communist Party of China, it is easy to find that this is a kind of theoretical achievement upon combination of ordinary principles of the CCP's socialist value outlook with development of our socialist undertakings. In other words, this achievement of thought theory plays a role in guiding and promoting initial development stage of our socialism. "Marxist guiding thought" is the statement of thoughts, theories and core thoughts formed upon combination of our socialist development. Moreover, "common ideal of socialism with Chinese characteristics” pointed a path for our development, expressing the people's supplication for national development. At the same time, the CCP also took this as the foundation of development. It made continuous efforts and contributions to construction of a harmonious socialist society. According to current situation of social development, patriotism is priority among priorities for a country to standing in world culture. As the core ideological system, it should lay emphasis on whether to master the pulse of era development in the development stage of patriotism. In the exchange process between our traditional culture and world culture, we should absorb essence discard dross, combine advantages of various excellent cultures, and form our socialist patriotism with this as development premise. We cannot overlook the beneficial function of socialist concept of honor and disgrace generally implemented in the society in standardizing Chinese people's daily life. Thought boundaries of national and social systems are included in guiding thought and ideology of our socialist value outlook, namely development strategy of "socialism with characteristics" proposed in the stage of socialist development. In terms of development structure of socialist value outlook stated above, our socialist value outlook reflects a supreme development trend of mutual independence and mutual promotion. At the same time, this advanced socialist value system constitutes the basic framework of the current socialist value outlook in China. The report on the CCP's $18^{\text {th }}$ Congress summarized the core thought of our socialist value outlook. Both items are mutually supplementary with the statement on socialist value outlook in the Sixth Plenary Session of the Sixteenth Congress of the Communist Party of China. In terms of their difference, the former advocated Chinese socialist core values. It is clearer and brighter in expression. State level, social level and personal cultivation are unscrambled with four groups of words, fully expressing advanced thought of our socialist core values.

\section{Advantages of socialist value outlook in world culture}

Different historical conditions and historical background will result in lots of different values. For value in specific historical period, it inevitably has its advancement and superiority. Under current historic opportunities, cultural exchange breaks restraints from time and space. It becomes more frequent for cultural collision, contact and exchange. We don't deny advancement of western mainstream cultural values, because any mainstream culture in the society has its advancement. Culture can be accepted and adopted by other excellent cultures, only when this culture has its traits of advancement, openness and deep influence. In terms of culture, it is undoubtedly socialist culture 
with deep historical details. In the exchange process with world culture, it is not inferior to any advanced culture in any respect. In the current world culture exchange, Chinese socialist culture shows great influence and vitality, which tells us that our socialist culture is self-confident. As a socialist system, its advancement is quite superior. Socialist value outlook generated on this basis is undoubtedly of great advancement. Throughout historical development, China had a variety of social forms in the process of historical changes. However, any ideology's advancement can be paralleled with the current socialist ideology. Chinese socialism is limited by a short development period, and differences exist between the strength of socialism in the world and western capitalist society. However, western mainstream social value cannot achieve the historical development trend reflected in socialist value outlook. Socialist value outlook is served as a high ground in current people's values. Its vitality and guidance are convincing. Therefore, we are confident of advancement of socialist system. At the same time, socialist value outlook is not windy. Any value cannot parallel with its importance attached to social practice. Practice is the sole criterion for testing truth. Undoubtedly, this statement on socialist value outlook is essentially common cognition of thought of numerous proletariats and Chinese laboring people. In its initial stage, Marxism pointed out that socialist ideological value system would inevitably replace capitalism and some old-fashioned values. In the current process of social development, it is continuously proved by people and history. Therefore, we are incomparably confident of socialist value outlook system.

\section{Differences between Socialist Value Outlook and Western Mainstream Value}

Value refers to manifestation of consciousness of social development stage. Different values will be generated in different stages of social development. Therefore, we should see clearly differences between Chinese socialist value outlook and western mainstream value. At first, it is necessary to distinguish Chinese socialist value outlook from western mainstream value. Inevitably, cultural characteristics left by historic culture will act on the current values. In the exploration for history development process, therefore, we should analyze differences between Chinese and western cultures from the perspective of traditional culture.

\section{Religious theology culture and family patriarchal culture}

Compared with family patriarchal culture formed in Chinese historical development, religious theology culture generated in western society in the corresponding historical period is also an important influence factor of culture in the history. As main realization Christian of religious ideology, it ruled the thought of western people for almost a thousand of years. Values and behavioral patterns formed in this historical period will inevitably have important influence on the formation of western mainstream values in the future. Western religious theology value emphasizes original sin. Therefore, humans and world must be kind with others in real society, so as to prove their goodness and belief to the God and thus enter the paradise. While facing incompatible values, Christian culture advocates collision and contact of different value systems with destruction and conquest as main means. Different from western religious theology values, China approves social values [2] with family patriarchy as main bond support. In Chinese traditional ideology, family is stressed instead of the God, especially for genetic connection. Comparatively, western culture emphasizes individual; while Chinese culture stresses filial piety and fraternal duty. At the same time, state structure is usually constructed with family pattern as main system. It is quite clear for hierarchical division of relationship in the structure. Therefore, Chinese people always hold attitudes of tolerance and peaceful coexistence while facing different ideological systems.

\section{Individualism and collectivism}

In the revolution period of western civilization, it is common for infusion of individualistic ideology. For Chinese and western culture, China takes patriarchal clan family as main value identification. Inevitably, its cognition of thought is always based on collectivism. However, western countries lay great importance to individual development. Therefore, it is obvious for differences in individual and collective ideological values. Western countries emphasize individualistic heroism and exertion of personal competence. In most cases, individuals with excellent performance will be 
highly praised. Sometimes, their defects can even be neglected. In China, models are also advocated. In western values, a hero's defects are neglected. However, Chinese people will see heroes' contributions to the society and their morals while judging their performance.

\section{Utilitarianism and ethicism}

Among influential factors in western ideological value system, influence of utilitarianism is obvious. The reason is the pursuit of western capitalist production mode for economic interest. At the same time, this value cognition has already formed deep-rooted cognition of thought in western society. Utilitarianism can also be found in Chinese traditional culture, but it emphasizes ethicism in the conflict between ethicism and utilitarianism ${ }^{[3]}$. The sacrifice value system is of important influence in traditional culture.

\section{Conclusions}

Socialist value outlook is the ideological achievement tested by history and people. Its moral sentiments and civilization philosophy reflected in current society make our living environment sharply demarcated from all decayed and laggard moral ideas. At the same time, this advanced value system has already been accepted by all Chinese people. Moreover, it has also become an example of social morality. Chinese traditional culture has deep deposits. In its construction process, therefore, Chinese socialist value system fully absorbed excellent thought achievements in thousands of years. Therefore, such combination makes Chinese traditional culture to be carried forward and developed. At the same time, it also provides a better exchange atmosphere for socialist value outlook. The more national colors a building reflects, the more attractive it is to the world. Chinese traditional culture going through thousands of years results in inexhaustible sources of thought for us in the process of cultural exchange with the world. Therefore, Chinese socialist core values will get better development under such source of thought.

\section{Acknowledgments}

This paper is the youth fund project of Wuhan Donghu University in 2013 (project name: Research on Activity Carriers of Socialist Core Values).

\section{References}

[1] Dong Peng and Jia Lianzhe, Differences between Chinese Socialist Value Outlook and Western Mainstream Value, Journal of the Party School of Shengli Oilfield, 2014 (1);

[2] Yang Xuegong, Conflict and Prospect of Current Values in China, Tianjin Social Sciences, 2013 (7);

[3] Lin Yuliang, Impact of Western Consumerism on Chinese Mainstream Value, Journal of Party College of Sichuan Province Committee of CCP, 2013 (12). 